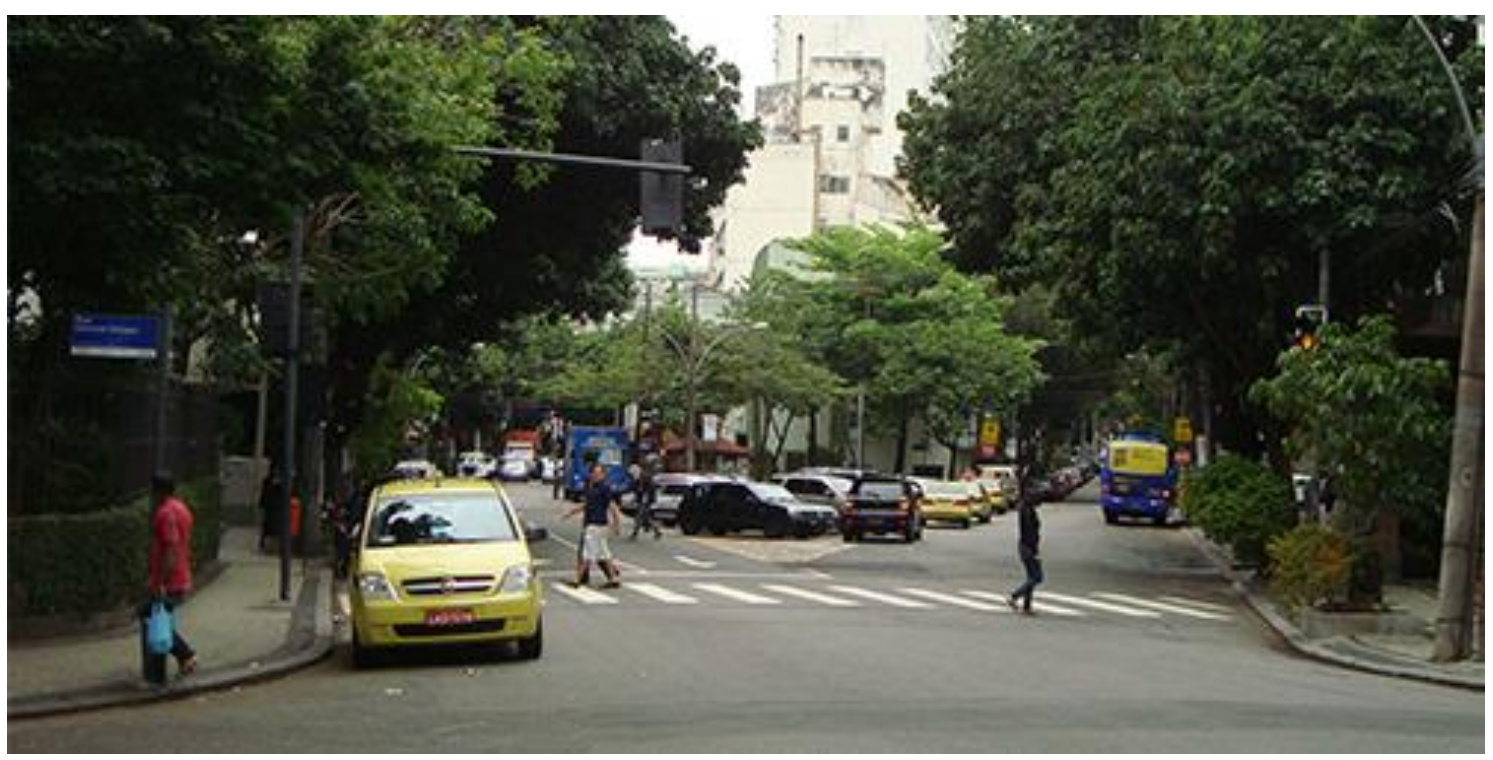

\title{
As ruas comerciais, o consumo e a vida social urbana: o universo dos ateliês da Rua Dias Ferreira
}

Commercial streets, consumption and urban social life: the ateliers in Dias Ferreira Street

Sílvia Borges Corrêa ${ }^{1}$

Resumo: Neste artigo procura-se descrever as práticas de comercialização, de consumo e de sociabilidade presentes na Rua Dias Ferreira, rua da cidade do Rio de Janeiro que se destaca pela presença de ateliês de moda feminina. Balizado por uma pesquisa etnográfica, o estudo se insere na perspectiva antropológica do consumo e, portanto, lança luz aos aspectos de linguagem coletiva, de comunicação e de classificação social presentes nas práticas comerciais que ali se desenrolam.

Palavras-chave: comércio de rua; consumo; sociabilidade; etnografia.

Abstract: This article analyzes practices of commerce, consumption and sociability in Dias Ferreira Street, Rio de Janeiro, a street characterized by the presence of female fashion ateliers. Conducted as an ethnographic research, the study emphasizes the anthropological perspective of consumption and thus reinforces aspects concerned with collective language, communication and social classification that take place in that street.

Keywords: commerce; consumption; sociability; ethnography

\footnotetext{
${ }^{1}$ Professora e pesquisadora da ESPM Rio. Doutora em Ciências Sociais pelo PPCIS/UERJ (Programa de Pós-Graduação em Ciências Sociais da Universidade do Estado do Rio de Janeiro) Rua do Rosário 111 $3^{a}$ andar - sala do Núcleo de Pesquisa. 20.051-060 - Centro - Rio de Janeiro - RJ. email: sborges@espm.br/silborgesc@gmail.com
} 
Os dicionários dizem: "Rua, do latim ruga, sulco. Espaço entre as casas $e$ as povoações por onde se anda $e$ passeia". (...) A rua era para eles apenas um alinhado de fachadas, por onde se anda nas povoações... Ora, a rua é mais do que isso, a rua é um fator da vida das cidades, a rua tem alma! (...)

Oh! sim, as ruas têm alma! Há ruas honestas, ruas ambíguas, ruas sinistras, ruas nobres, delicadas, trágicas, depravadas, puras, infames, ruas sem história, ruas tão velhas que bastam para contar a evolução de uma cidade inteira, ruas guerreiras, revoltosas, medrosas, spleenéticas, snobs, ruas aristocráticas, ruas amorosas, ruas covardes, que ficam sem pinga de sangue...

(A alma encantadora das ruas, João do Rio)

\section{Introdução}

Este artigo tem como objetivo central a descrição e a análise das práticas de comercialização e de consumo, bem como dos aspectos de sociabilidade presentes na Rua Dias Ferreira, na Zona Sul da cidade do Rio de Janeiro. Essa rua, localizada no Leblon, um dos bairros com os imóveis (residenciais e comerciais) mais caros da cidade e onde residem predominantemente pessoas das classes alta e média alta, se destaca pela presença de ateliês de moda feminina, de restaurantes e bares bastante conhecidos no cenário gastronômico carioca, e de "famosos" e "celebridades" que por ali circulam. A proposta central deste trabalho, resultante de uma pesquisa de cunho etnográfico, é destacar as questões socioculturais que permeiam algumas das práticas comerciais que se desenrolam naquele lugar, em particular aquelas relacionadas aos ateliês de moda que, ao longo dos últimos dez, quinze anos, se instalaram na Dias Ferreira.

\section{Algumas reflexões sobre as ruas comerciais e a vida urbana}

As ruas das grandes cidades brasileiras são espaços privilegiados para a compreensão das dinâmicas urbanas no que tange ao consumo, ao trabalho, ao lazer e à sociabilidade; enfim, às relações sociais presentes no espaço urbano. Em tempos de construção de novos e de remodelação ou expansão de antigos shopping centers nas cidades brasileiras, é interessante perceber alguns exemplos de "resistência" ou de (re)florescimento do comércio de rua nas nossas cidades. Historicamente, o comércio representa um elemento importante de desenvolvimento da vida social e, atualmente, o comércio ganha novos contornos devido à centralidade do consumo na vida moderna. Uma visão mais apocalíptica, que poderia vaticinar a total decadência ou mesmo a 
extinção do comércio de rua, face ao crescimento do número de shopping centers, aliado ao aumento das cifras do e-commerce, desconsideraria que essas modalidades de comércio nem sempre são concorrentes, pois representam espaços de consumo diferentes, que, ao que temos observado nos últimos anos, tendem a ser complementares. Aquilo que se busca nas lojas e nos espaços de shoppings não é necessariamente o que se busca nas lojas localizadas fora desses espaços - em termos de produto, preço, atendimento etc. Além disso, do ponto de vista dos consumidores, muitas vezes os shopping centers suprem algumas deficiências relativas à carência de espaços de lazer e/ou de falta de segurança das cidades, mais do que a falta de opções de comércio.

De que forma então, seria possível perceber a "resistência" ou (re)florescimento do comércio de rua em algumas cidades brasileiras? O que esses exemplos poderiam nos sinalizar em termos de análise da configuração atual e de perspectivas para as atividades comerciais?

Uma primeira gama de exemplos seria composta pelas tradicionais ruas de comércio específico, que resistem, às vezes com dificuldades, é verdade, às transformações impostas pela dinâmica urbana. As ruas de comércio especializado são aquelas em que há forte presença, clara predominância ou mesmo exclusividade de um segmento de comércio. Nessas ruas é possível encontrar uma concentração de lojas que comercializam um mesmo tipo de mercadoria. Compreender a dinâmica dessas ruas, buscando mostrar as trajetórias que as levaram a se tornar ruas de comércio especializadas em um tipo de produto - ou, em alguns casos, mostrar que mudanças podem, ao contrário, fazer com que esse caráter de especificidade seja reduzido, abrindo espaço para a existência de outros tipos de lojas e produtos, é um ponto de partida para a compreensão das transformações ocorridas nas relações de consumo, de trabalho e de comércio. $\mathrm{Na}$ cidade do Rio de Janeiro algumas ruas são conhecidas por se dedicarem à comercialização de um tipo específico de produto: os antiquários da Rua do Lavradio; os lustres e materiais de iluminação da Rua Senador Bernardo Monteiro (mais conhecida como Rua dos Lustres); as lojas de móveis da Rua do Catete; as lojas de instrumentos musicais da Rua da Carioca; e os produtos populares da Rua da Alfândega. As ruas especializadas também fazem parte do cenário urbano do Recife - como, por exemplo, a Rua da Concórdia, que concentra lojas de instrumentos musicais, e a Rua do Aragão, tradicional ponto de lojas de móveis - e de São Paulo - com destaque para a Rua Oscar Freire, conhecida nacionalmente por suas lojas de luxo; a Rua Cardeal Arcoverde e seu comércio de antiguidades; a Avenida Dr. Arnaldo, com ativo comércio de flores; a Rua São Caetano, 
onde se concentram lojas de vestidos de noiva, entre tantas outras. Esses são apenas alguns exemplos do diversificado universo das ruas onde é possível encontrar concentração e predomínio de um tipo de comércio. Os exemplos não se restringem às cidades citadas ou ao Brasil, e, embora, como fenômeno, possam não ser comparáveis em termos históricos e sociológicos, as ruas de comércio especializado estão presentes em várias cidades europeias. Portobello Road, no bairro de Notting Hill, em Londres, que concentra um incrível número de antiquários; Brick Lane, também em Londres, e Carrer de la Riera Baixa, no bairro do Raval, em Barcelona, ambas conhecidas por suas lojas de roupas de segunda-mão (especialmente vintage); as ruas do Triangle d'Or, em Paris, com suas butiques de luxo. Nesses e em outros países, o comércio de rua é visto como algo estimulante à vida econômica e social das cidades, e é incentivado e divulgado pelo poder público e pela iniciativa privada. Em Paris, por exemplo, a prefeitura da cidade, reconhecendo a importância do comércio na vida social parisiense, tem estimulado e apoiado a realização de feiras nos bairros. Em Londres foi publicado um guia que lista, localiza e descreve os mais de 70 mercados e feiras de rua da cidade - The London market guide (KERSHMAN, 2008). Em Amsterdã, os vários mercados e feiras de rua existentes - de alimentos, de roupas de segunda-mão, de livros, de flores e plantas - constam do mapa turístico da cidade ${ }^{2}$.

Outro tipo de exemplo é o de ruas que passam, mais recentemente, a ter destaque no cenário comercial e social das cidades, e cujas "fama" e área de influência podem, inclusive, ultrapassar as barreiras locais. Quanto a esse tipo de rua, que exemplifica o (re)florescimento do comércio de rua, pois, não sendo um reduto tradicional de comércio, ganham destaque no cenário econômico e social da cidade, destaca-se, na cidade do Rio de Janeiro, a Rua Dias Ferreira, rua da zona sul carioca que, nos últimos dez anos, se tornou conhecida por concentrar ateliês que comercializam moda feminina (roupas e acessórios). São os resultados de uma pesquisa realizada na referida rua que passam a ser apresentados a seguir.

\section{A pesquisa na Rua Dias Ferreira}

No que tange à seleção da rua pesquisada, a escolha recaiu sobre uma rua que representasse um caso recente, datado de aproximadamente uma década, de um local que

\footnotetext{
${ }^{2}$ Não se trata de estabelecer neste artigo uma comparação entre as ruas citadas, uma vez que os universos são absolutamente diversos e distintos; trata-se apenas de apresentar exemplos nacionais e internacionais que possam trazer à tona a existência de ruas de comércio especializado.
} 
tivesse se transformado em uma referência de comercialização de bens e/ou serviços para a cidade do Rio de Janeiro.

Quanto ao tipo de pesquisa, tratou-se de uma pesquisa exploratória de cunho antropológico, tendo como ponto de partida o referencial teórico da Antropologia do Consumo e sendo conduzida a partir do método de pesquisa etnográfico. Tradicional método de pesquisa antropológica, o método etnográfico não busca regras gerais ou leis universais, mas sim descrever e interpretar os fenômenos sociais e compreender as lógicas, os valores e os significados presentes numa coletividade a partir do "ponto de vista nativo". Os estudos de cunho etnográfico, portanto, são orientados por um tipo de conhecimento científico que é gerado a partir do ponto de vista do outro, permitindo uma pesquisa por dentro da realidade de um grupo, escapando do viés etnocêntrico através de um olhar relativizador. A centralidade do saber e do fazer antropológico está, para Peirano (1991), na tensão criativa entre teoria e pesquisa; tensão permanente entre o saber acumulado na disciplina e as "categorias nativas" apresentadas pelos integrantes dos grupos sociais pesquisados. O método etnográfico preconiza a realização de um trabalho de campo no qual são utilizadas duas técnicas que se complementam na construção da “descrição densa" de um grupo, evento ou fenômeno social: a observação participante e as entrevistas em profundidade.

O referencial teórico da pesquisa se insere na área do conhecimento denominada Antropologia do Consumo, cujo enfoque procura acentuar a dimensão cultural que atravessa as práticas de consumo. Nesse sentido, o consumo deve ser entendido como um processo sociocultural - que envolve, além do uso, a troca e a criação de bens e serviços. De acordo com a visão antropológica sobre o consumo, as respostas para a pergunta "por que consumimos?" são diversas: consumimos para mediar nossas relações sociais, para conferir status, para construir identidades, para estabelecer fronteiras entre grupos e pessoas (processos de inclusão e de exclusão social), para classificar, para expressar nossos desejos, nossas aspirações e nossos afetos. Enfim, trata-se de analisar o consumo de uma perspectiva que não reduza esse fenômeno social a uma dimensão meramente econômica ou utilitarista, mas que, ao contrário, ressalte os aspectos de linguagem coletiva, de comunicação e de classificação social presentes no consumo moderno (DOUGLAS \& ISHERWOOD, 2004; SAHLINS, 1979).

Do ponto de vista antropológico, os bens apresentam um duplo papel: de um lado, sem dúvida, provêm subsistência, mas, de outro, promovem relações sociais. É neste sentido que se torna possível afirmar que o consumo pode ser entendido como uma forma 
de comunicação entre as pessoas, na qual os objetos atuam como mediadores ou indexadores desse processo interativo: os bens são comunicadores. Numa simples frase, “as mercadorias são boas para pensar” (DOUGLAS \& ISHERWOOD, 2004, p. 108). Logo, servem para produzir sistemas classificatórios a partir dos quais os grupos sociais demarcam fronteiras e diferenças entre si.

Em vez de supor que os bens sejam em primeiro lugar necessários à subsistência e à exibição competitiva, suponhamos que sejam necessários para dar visibilidade e estabilidade às categorias da cultura. É prática etnográfica padrão supor que todas as posses materiais carreguem significação social e concentrar a parte principal da análise cultural em seu uso como comunicadores. (...) As posses materiais fornecem comida e abrigo, e isso deve ser entendido. Mas, ao mesmo tempo, é evidente que os bens têm outro uso importante: também estabelecem e mantêm relações sociais. (Douglas \& Isherwood, 2004, p. 105)

Esqueçamos que as mercadorias são boas para comer, vestir e abrigar; esqueçamos sua utilidade e tentemos em seu lugar a ideia de que as mercadorias são boas para pensar: tratemo-las como um meio não verbal para a faculdade humana de criar. (Douglas \& Isherwood, 2004, p. 108)

Sob essa perspectiva cultural, espaços de comércio e consumo são lugares nos quais e a partir dos quais é possível perceber e analisar especialmente uma das dimensões do consumo: a troca, ou seja, a comercialização - em seus mais variados aspectos. Apesar da existência de clássicos na literatura antropológica, tais como Malinowski (1976), com seu estudo sobre o kula nas Ilhas Trobriand, e Mauss (2001), com seu trabalho sobre o potlach entre tribos indígenas da América do Norte, que são exemplos de análises detalhadas sobre a dimensão social das trocas, nas atuais pesquisas brasileiras, de caráter antropológico, sobre o consumo, a troca tem se apresentado como um aspecto não muito estudado em detrimento de aspectos relacionados ao uso dos produtos e serviços. Há também que se ressaltar que a produção acadêmica nacional sobre espaços de consumo tende a privilegiar pesquisas sobre shopping centers (CAVEDON \& LENGLER, 2002; COSTA et al., 2000; FRÚGOLI JR, 1992; SOARES, 2000; UNDERHILL, 2004). Especificamente sobre comércio de rua, o levantamento bibliográfico realizado apontou para a existência de poucos estudos no campo da Antropologia e da Sociologia, entre eles dois sobre a SAARA-Sociedade dos Amigos e das Adjacências da Rua da Alfândega (BARROS, 2002; CUNHA \& MELLO, s/d), região de comércio popular no centro do Rio de Janeiro e outros dois sobre ambulantes (MARTINELI, 2009; BARROSO, 2008) - o primeiro sobre ambulantes das ruas de Ipanema, bairro da zona sul do Rio de Janeiro, e o segundo sobre ambulantes da Rua Voluntários da Pátria, na cidade de Porto Alegre. 
$\mathrm{Na}$ literatura antropológica internacional existe um trabalho seminal e que se tornou a principal referência para a pesquisa sobre a Rua Dias Ferreira. Trata-se do trabalho de Geertz $(1978,1979)$ que, em seu estudo sobre sistemas de mercados tribais/regionais ( "peasant market systems") ou aquilo que ele denomina de economia de bazar ( "bazaar economy”), revela a centralidade do mercado na estruturação de algumas sociedades. A partir de sua pesquisa na cidade de Sefrou, no Marrocos, o autor descortina questões importantes para o entendimento das relações sociais nessa sociedade. O bazar é um sistema particular de relações sociais centrado em torno da produção e do consumo de bens e serviços, ou seja, é um tipo particular de economia. Nesse sistema, a informação é escassa, mal distribuída, ineficientemente comunicada e intensamente valorizada. $\mathrm{O}$ nível de ignorância ou desconhecimento sobre tudo - da qualidade dos produtos aos preços praticados - é alto. Como consequência, o "jogo" do bazar consiste na busca por informações por aqueles que não as têm e a proteção da informação por parte daqueles que as possuem. Para Geertz (1978, p. 30), "the search for information is the central experience of life in the bazaar" ("a procura por informação é a experiência central da vida no bazar"). Mais do que troca de produtos, trata-se da troca de habilidades cuja ênfase recai sobre o conhecimento a respeito de que tipo de mercadoria está sendo vendida e para que fins a mesma está sendo vendida. Nesse contexto de trocas simbólicas, dois procedimentos de busca são fundamentais: a "clientelização" e a barganha. O primeiro pode ser entendido como a tendência a compras repetitivas de bens e serviços específicos a fim de estabelecer relações contínuas (situação oposta a da procura pelo mercado a cada nova ocasião de compra) e representa uma maneira de lidar com as deficiências de informação no bazar. A barganha, por sua vez, tem um caráter multidimensional e intensivo, uma vez que qualidade, quantidade e outras dimensões não monetárias podem ser barganhadas, o crédito pode ser negociado, etc. Apesar de ressaltar a especificidade do suq (bazar) de Sefrou - sua formação, seu desenvolvimento, sua heterogeneidade e suas características étnicas, os textos de Geertz $(1978,1979)$ lançam bases para a análise de outras configurações de comércio, uma vez que analisam o bazar em sua estrutura física (organização espacial, segmentação, setores etc.) e em sua forma social (divisão de trabalho, relações entre comprador e vendedor, financiador e tomador de empréstimo, profissional e leigo) - aspectos que podem orientar o olhar etnográfico para diferentes locais de troca e formas comerciais.

Assim, tendo os referidos trabalhos de Clifford Geertz como inspiração e balizado pelo método etnográfico, o trabalho de campo da pesquisa foi realizado, durante 
aproximadamente dez meses, com observação direta na rua e nos estabelecimentos comerciais, e entrevistas em profundidade com comerciantes, preferencialmente proprietários e gerentes dos ateliês de moda. Cabe registrar que o gênero masculino está sendo utilizado para a referência aos comerciantes e aos consumidores da Rua Dias Ferreira, mas o universo dos ateliês ali localizados é predominantemente feminino, com pouca presença de representantes do sexo masculino nos trechos da rua e nos prédios nos quais se localizam esses ateliês. No entanto, a rua em geral, especialmente por conta dos restaurantes e bares, que contribuem significativamente para o movimento e o trânsito de pessoas existentes na Dias Ferreira, conta com a presença também do sexo masculino, diluindo o predomínio da presença feminina na rua como um todo.

Localizada no Leblon, região nobre da Zona Sul da cidade, a Rua Dias Ferreira foi a primeira rua aberta no bairro $^{3}$ - chamada de Rua do Pau - e atualmente é conhecida por abrigar bares e restaurantes modernos e ateliês de moda feminina, especializados naquilo que poderia ser chamado de "vanguarda" ou "tendência". Como descrito pela mídia em várias ocasiões, a Dias Ferreira reúne "gastronomia, moda e gente bonita" (CERQUEIRA, 2007), numa clara referência não só aos estabelecimentos comerciais, mas também aos freqüentadores da rua, pois esses restaurantes e ateliês atraem artistas e pessoas das classes média-alta e alta cariocas. Passou a ser considerada uma "rua-vitrine" do Rio de Janeiro por encarnar aquilo que poderia ser descrito como o estilo "sofisticado carioca", que incorporaria a descontração e o despojamento típicos do "jeito de ser carioca" à sofisticação do comércio presente naquela rua da Zona Sul da cidade.

\footnotetext{
${ }^{3}$ Não há consenso sobre o primeiro nome da Rua Dias Ferreira ter sido Rua do Pau, pois, em algumas referências, Rua do Pau é o antigo nome da Rua Conde de Bernadote. Diferente do que acontece com outras ruas da cidade do Rio de Janeiro, cujas histórias são bem documentadas, para a Rua Dias Ferreira praticamente inexistem referências sobre sua história.
} 


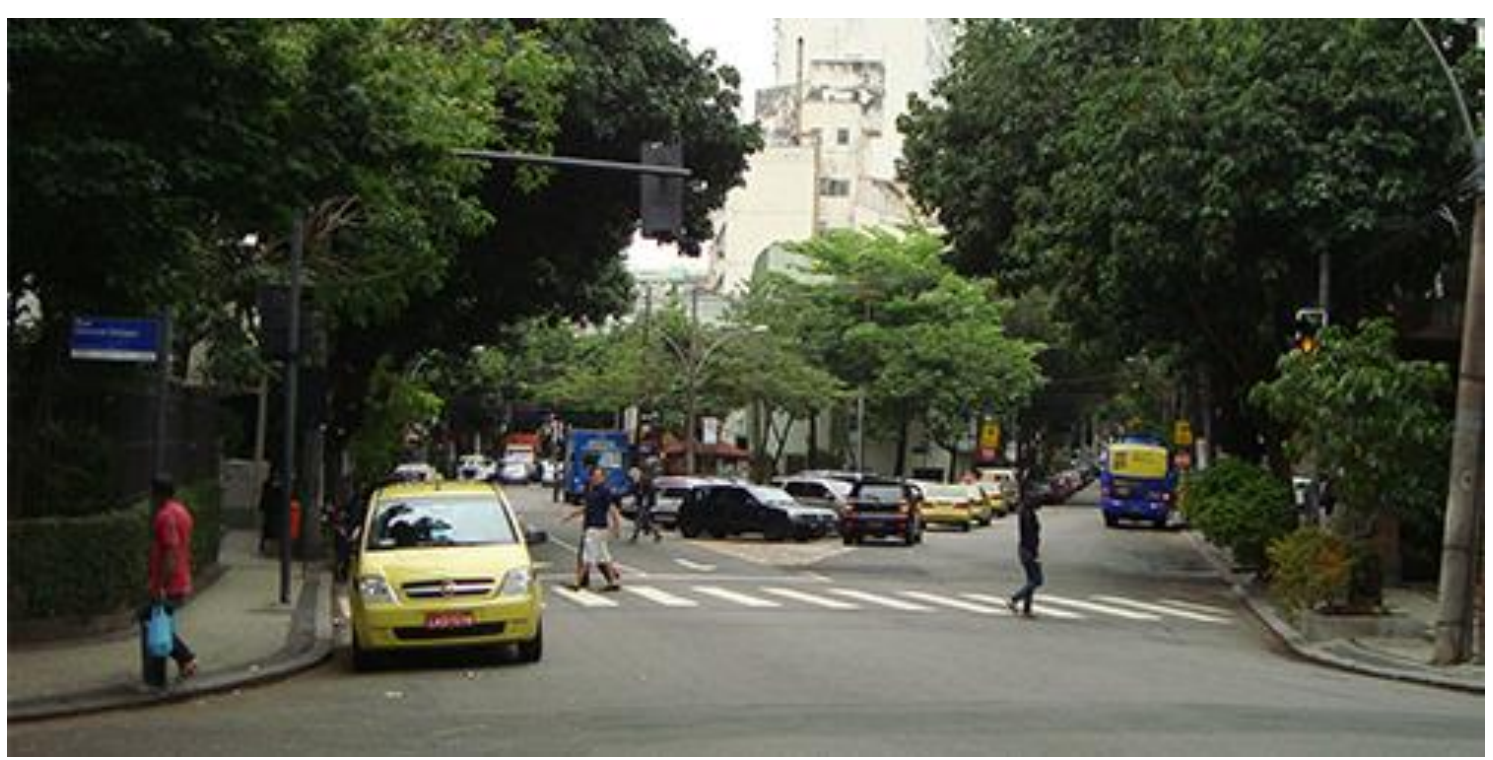

Foto da autora. Visão geral da Rua Dias Ferreira.

Na Rua Dias Ferreira é possível encontrar prédios residenciais e estabelecimentos comerciais; estes são de tipos variados, tais como supermercados, farmácias, papelarias, salões de beleza e lavanderias, mas há claramente uma concentração de restaurantes e de lojas de roupas e acessórios femininos, entre elas os ateliês. Numa contagem feita in locco foram contabilizados 27 restaurantes e bares ${ }^{4}$ em funcionamento. Em relação aos ateliês instalados na Dias Ferreira, chegou-se ou número de $24^{5}$. A dinâmica comercial da rua, com a abertura de novos e o fechamento de antigos ateliês, e as possíveis diferentes definições de ateliês, podem acarretar variações nesse número, mas, em todos os registros comerciais e jornalísticos consultados, o número de ateliês girava, à época do trabalho de campo realizado, em torno de 25 . Também não há uma precisão em relação a quando os ateliês começaram a se instalar na Dias Ferreira, mas as entrevistas realizadas apontam para os primeiros anos de 2000, entre 2001 e 2003, como o período da chegada e instalação dos pioneiros. Foram classificados como ateliês aqueles estabelecimentos que se caracterizam por comercializar mercadorias (roupas, jóias, acessórios, objetos decorativos) de produção própria em pequena escala. São estabelecimentos comerciais que se concentram em três prédios ao longo da rua; prédios de três ou quatro andares nos quais o acesso às lojas é possível apenas por escada. Em dois desses prédios também podem ser encontradas lojas que comercializam produtos que não são de fabricação própria, mas essas lojas guardam uma espécie de afinidade com os ateliês, ou como

\footnotetext{
${ }^{4}$ Esta categoria inclui, além de restaurantes e bares, lanchonetes, bistrôs, botequins e uma casa de chá.

${ }^{5}$ Esse número é resultado de uma contagem pessoal feita na rua, no mês de julho de 2010.
} 
algumas entrevistadas revelaram, são lojas que têm um "clima de ateliê". "Clima de ateliê" significa que o espaço é intimista e acolhedor, que a relação entre comerciantes e consumidores é muito próxima - que muitos afirmam ser uma relação de amizade, e que os produtos são exclusivos, personalizados e/ou de produção limitada.

Assim, utilizar o termo "ateliê", em vez de loja, pode se revelar um atrativo especial, como fica claro no informe publicitário de um dos prédios, que se intitula como o "QG dos ateliês mais sofisticados e despretensiosos da cidade. (...) é um verdadeiro recanto tradicional com perfume fashion no coração do Leblon" (3R Studio Comunicação, s/d, p. 3 e 4). Já o folder de uma loja de sapatos instalada naquele prédio fala em "endereço mais charmoso do Rio".

Em relação ao espaço físico dos ateliês, o tamanho das salas varia entre 30 e 40 metros quadrados, e há claramente uma preocupação com a decoração do ambiente: paredes pintadas com cores marcantes ou decoradas com papéis de parede floridos e estampados; cortinas; espelhos; puffs; enfim, elementos que possam dar ao ambiente uma atmosfera de "luxo e despojamento", nas palavras de uma entrevistada. Alguns ateliês são descritos por seus proprietários como um "ambiente que insere o luxo no clima despojado da cidade"; outros fazem questão de destacar o clima "aconchegante, como a casa de uma amiga", numa clara e referida oposição a "loja de shopping”, categoria frequentemente utilizada como contraponto à categoria "ateliê", que seria um tipo de loja na qual o atendimento é cuidadoso e atencioso, e que, do ponto de vista desses profissionais, não é possível oferecer em lojas mais movimentadas - e nem mesmo nas lojas mais sofisticadas - instaladas em shopping centers.

Com relação aos horários de funcionamento dos ateliês, há bastante flexibilidade, mas a maioria costuma abrir às 10 horas - alguns só abrem após as 12 horas - e permanecer aberta até as 19 ou 20 horas, de segunda a sexta-feira, e até as 14 horas aos sábados. Ainda em referência aos horários e ao tipo de atendimento dispensado aos clientes, elementos interessantes de serem observados são as pequenas placas com a inscrição "Volto logo" - algo típico dos antigos estabelecimentos comerciais de bairro ou de cidades de interior - afixadas às portas dos ateliês quando a ausência do comerciante é necessária, e isso acontece porque em muitos ateliês há apenas uma pessoa trabalhando. Esse recurso é mais frequentemente utilizado nos intervalos para almoço e, em alguns casos, há o cuidado de registrar nessas placas um número de celular através do qual os clientes podem entrar em contato com os comerciantes durante o período em que o ateliê permanece fechado. 
Em dois dos prédios, o acesso aos ateliês é direto e são mantidos em suas fachadas letreiros com a relação dos ateliês. Vários ateliês mantêm as portas fechadas e é preciso tocar a campainha; outros mantêm a porta permanentemente aberta - nesses casos não é incomum fechá-las total ou parcialmente caso perceba-se que isso dará mais privacidade aos clientes durante o processo de compra. Essa prática de deixar as portas permanentemente fechadas ou de fechá-las quando se pretende dar mais privacidade ao cliente, pode ser analisada, por um lado, como uma ratificação da circulação propositalmente restrita nos espaços dos ateliês, indicando a exclusividade característica desses espaços e, de outro lado, como uma maneira de garantir um espaço de sociabilidade também mais restritiva, próxima e pessoal entre comerciante e consumidor. No terceiro prédio é diferente, não há nenhuma indicação de que ali se encontram estabelecimentos comerciais, sendo preciso utilizar o interfone para contatar os ateliês estratégia que pressupõe que o consumidor saiba previamente o número da sala do ateliê que pretende acessar, parecendo haver certo segredo sobre o endereço desses ateliês ${ }^{6}$.

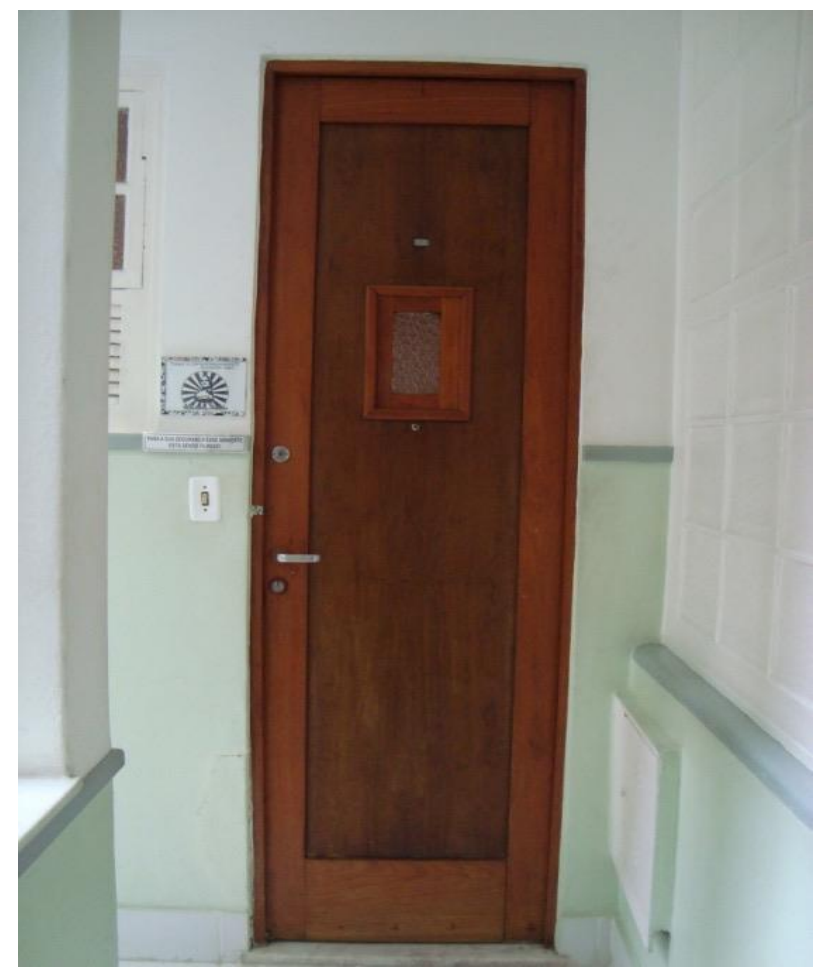

Foto da autora. Ateliê em funcionamento, mas com a porta mantida fechada.

\footnotetext{
${ }^{6}$ Em nenhum dos ateliês foi permitida a fotografia dos espaços internos, de seus detalhes de decoração e de seus produtos. As negativas às solicitações feitas podem ser interpretadas como um reforço às ideia de exclusividade, "aconchego" e "casa" que comerciantes procuram imprimir aos ateliês.
} 


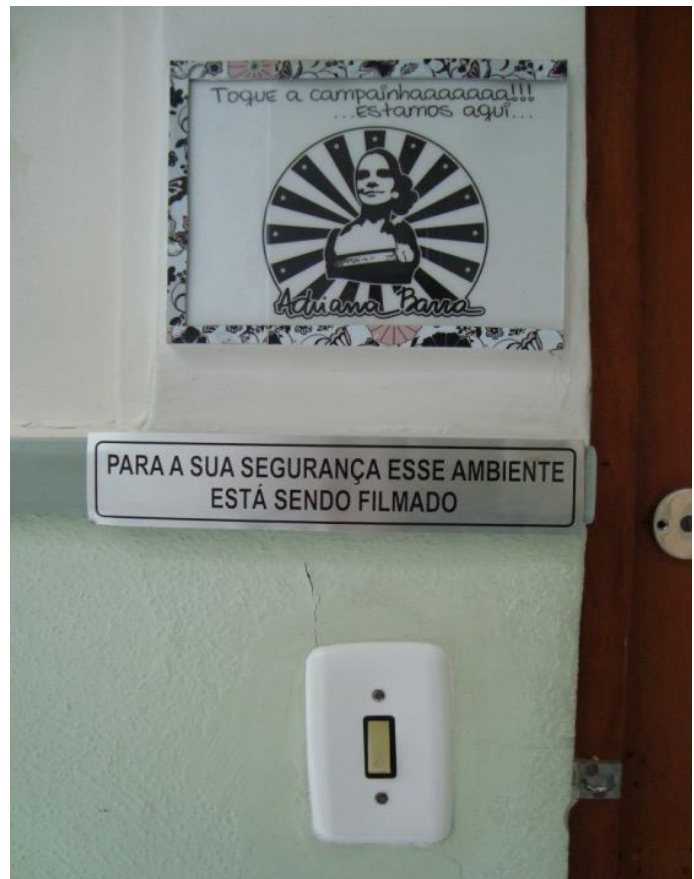

Foto da autora. Ateliê em funcionamento, mas com a porta mantida fechada. Detalhe da placa.

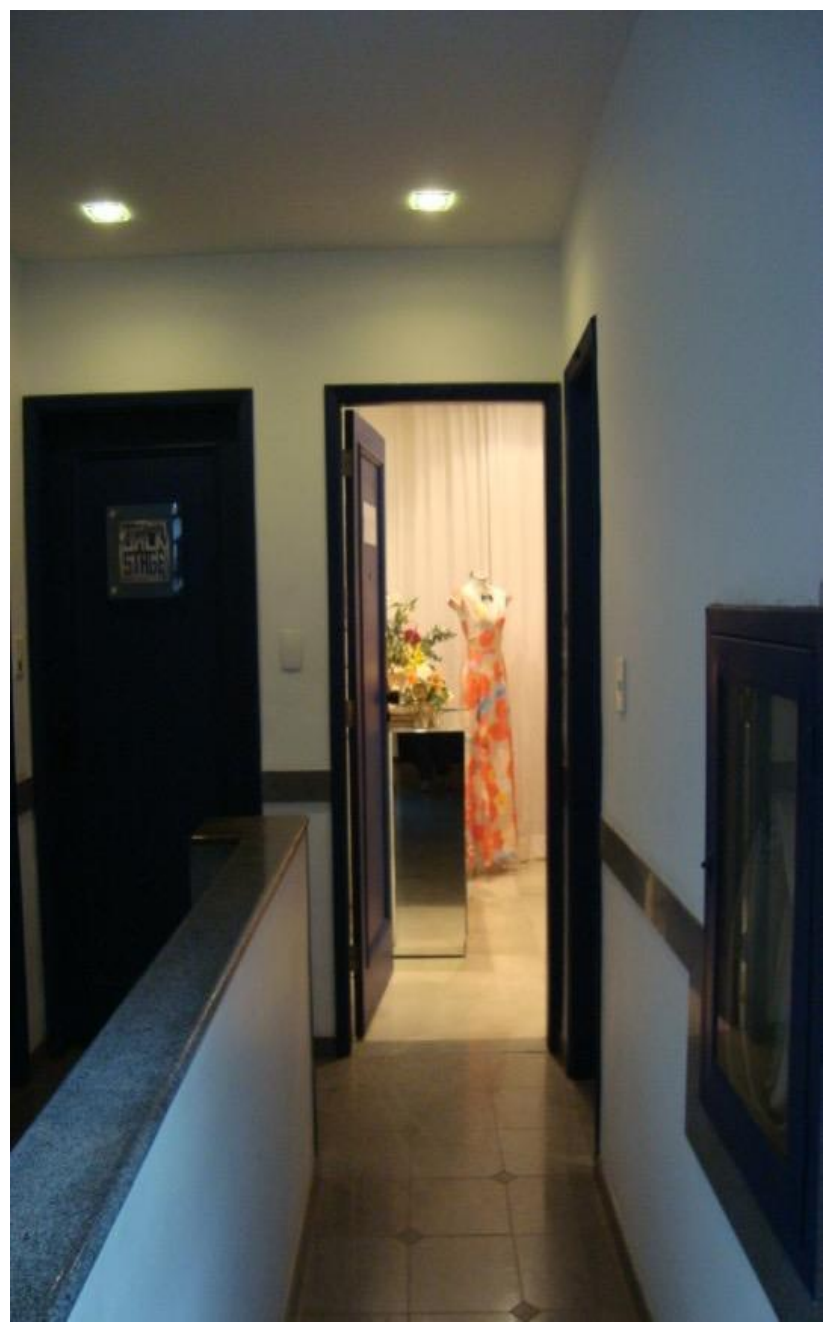

Foto da autora. Ateliê com porta aberta. 
Com relação às formas de divulgação utilizadas, parece valer o tradicional boca a boca. Embora quase todos os ateliês tenham sites na Internet e alguns produzam folders, categórica e unanimemente os comerciantes afirmam que a maneira mais utilizada e mais eficiente de divulgar seus espaços, seus produtos e atrair novos clientes é o boca a boca; é a indicação dos próprios clientes que realmente conta. Mesmo assim, ser citado em uma publicação de moda de destaque pode atrair novos clientes e divulgar a marca, e, por isso, é algo também valorizado.

Quanto às mercadorias que são comercializadas nos ateliês, o predomínio é de roupas e acessórios femininos, mas as joias também têm presença marcante entre esses estabelecimentos. Existe uma preocupação constante em comunicar e fazer com que os consumidores percebam que se trata de produtos exclusivos, personalizados, artesanais, que há poucas peças de cada modelo e que, por isso, dificilmente serão vistos sendo usados por outras pessoas; enfim, mais do que o tipo de mercadoria, aquilo que caracteriza e se destaca nos ateliês é o caráter de exclusividade da mercadoria. Em relação ao perfil dos consumidores que freqüentam os ateliês, suas proprietárias e gerentes descrevem as clientes como mulheres, predominantemente moradoras do Leblon e de outros bairros da Zona Sul, com um poder aquisitivo alto (classes alta e média-alta), entre 18 e 50 anos (dentro desta faixa etária pode haver variação de acordo com o ateliê), que "têm atitude e elegância" e, portanto, querem produtos exclusivos. Os ateliês são espaços que lançam moda e que, não sendo exatamente grifes de luxo, são representativos do estilo carioca de se vestir ou da moda carioca: uma moda "descolada" que traduz a "sofisticação carioca". É neste sentido que estar na Rua Dias Ferreira é importante, uma vez que a rua traduziria essa atmosfera "descolada" e "cariocamente sofisticada". O charme da rua é "emprestado" aos ateliês e é esta ideia que está presente entre suas proprietárias e gerentes que nas entrevistas revelam o prazer e também a importância da escolha do lugar para os negócios.

Por fim, mas ainda como elemento relacionado à sociabilidade que tem lugar na Rua Dias Ferreira, cabe mencionar os eventos que ali aconteceram e que ilustram o aspecto de coletividade entre os estabelecimentos comerciais do lugar. De acordo com registros e materiais impressos consultados, em 2006, o evento marcante foi o Deixa a rua te levar, realizado entre os dias 2 e 23 de dezembro de 2006, e apresentado no folder de divulgação como "um convite para reviver a tradição e simpatia do comércio de rua". Durante os dias do evento a rua recebeu decoração e programação especiais (palestras, 
degustações, shows, noites de autógrafos etc.), e alguns ateliês realizaram promoções e ofereceram descontos para as compras de Natal. O outro evento importante tem sido o Festival de Jazz (atualmente chamado de Leblon Jazz. Festival), um festival de música realizado desde 2008 e que já foi descrito como:

Um festival de Jazz \& Blues no bairro mais charmoso do Rio. O Itaipava Premium Leblon Jazz Festival chega com uma proposta inédita, levar música de qualidade e interatividade para o Leblon. O local não poderia ser mais apropriado, a Rua Dias Ferreira ficará fechada o para o trânsito. (...) Imaginese em um lugar charmoso, sentindo a brisa do inverno chegar, e soprando aos seus ouvidos uma bela melodia de Ella Fitzgerald, Billie Holiday, Buster Williams, John Coltrane, John Mclauglhin ou Miles Davis. Quer um cenário ainda mais perfeito? Então que tal um expresso com creme, flores ao redor e tudo isso ao ar livre. Este será o Itaipava Premium Leblon Jazz Festival, que trará aos cariocas a oportunidade de apreciar o melhor do Jazz, Blues e MPB, em um agradável espaço público. (...) Enquanto a boa música estiver deliciando os ouvidos, o público que lá estiver poderá também se refrescar, esquentar e degustar algumas das melhores guloseimas com a qualidade dos já renomados bares e restaurantes da Dias Ferreira, que dispensam qualquer apresentação. (http://www.amaleblon.com.br/).

Esses e outros eventos, como uma concorrida festa junina, em geral idealizados e liderados pelos donos da livraria e dos restaurantes, mobilizam e recebem apoio grande parte dos comerciantes instalados na rua, que são responsáveis por levar milhares de pessoas à Dias Ferreira e, desta forma, considerados também como elementos de comunicação e divulgação importantes. Interessante notar que, até onde pôde ser investigado ao longo do período da pesquisa, comerciantes e consumidores veem esses eventos de forma positiva, como algo que potencialmente traz consumidores para a rua, que dá lhe unidade e a torna mais conhecida não somente como um espaço de comercial, mas como um lugar de entretenimento, de atividade cultural e de lazer.

\section{Considerações Finais}

Espaços nos quais se pode perceber o estabelecimento e a manutenção de relações sociais variadas, além das óbvias funções ligadas ao intercâmbio de objetos e serviços e a geração de lucro, as ruas de comércio não devem ser vistas como sobrevivência do passado e nem como algo periférico a outros espaços e a outras dinâmicas econômicas, tais como os grandes shopping centers e os sites de compras da Internet. Particularmente no caso da Rua Dias Ferreira, a pesquisa mostra que os ateliês são estabelecimentos comerciais que, como proposta e como execução, se diferenciam tanto de lojas de shopping, como de lojas virtuais. Na Dias Ferreira, além do "peso" do nome da rua, existe um "espírito" de rua, isto é, percebe-se entre os comerciantes desses estabelecimentos um 
sentimento de pertencimento à rua como uma coletividade, sentimento que está presente nos discursos e na realização de atividades coletivas que agregam esses comerciantes, como os eventos organizados ao longo dos últimos anos. A rua pesquisada representa um caso em que o nome da rua confere aos estabelecimentos comerciais ali instalados uma simbologia positiva, de modo que aquela localização, por si, já representa uma espécie de garantia ou de certificação. Em outras palavras, a rua é um fator de reconhecimento a priori de qualidade; a rua é a grife e, portanto, estar naquela rua funciona como uma credencial ao estabelecimento comercial.

Além disso, diferentemente do que acontece em outras ruas comerciais, nas quais estão presentes conflitos entre diferentes atores sociais (sejam eles comerciantes, consumidores ou moradores $)^{7}$, na Rua Dias Ferreira as relações observadas tendem a ser harmoniosas, uma vez que os dois tipos de comércio predominantes apresentam complementaridade. Ateliês e restaurantes têm seus espaços bem demarcados e oferecem serviços que são complementares e não concorrentes. Além disso, embora a rua tenha um grande fluxo de consumidores por conta da presença desses estabelecimentos comerciais, a Dias Ferreira mantém uma dinâmica que garante um cotidiano urbano relativamente tranquilo para seus moradores

\section{Referências bibliográficas}

3R Studio Comunicação. s/d. Palm Beach: moda \& estilo. Rio de Janeiro.

AMALEBLON. <http://www.amaleblon.com.br>/. Consult. 06 de fevereiro de 2013.

BARROS, C. Um exercício de observação etnográfica na Saara. Cadernos Discentes COPPEAD, $\mathrm{n}^{\circ}$ 9. 2002.

BARROSO, P. F. Etnografia de rua na "Voluntários da Pátria": fotografando ambulantes no espaço público. Revista Ensaios, n.1, v.1, ano 1, 2008.

CAVEDON, N. \& LENGLER, J. Do "templo do consumo" à representação mitológica: um olhar etnográfico desconstrutivo sobre os ritos no shopping center. RIMAR-Revista Interdisciplinar de Marketing, v. 1, n. 2, p. 23-38, mai-ago, 2002

CERQUEIRA, S. A passarela do Leblon. Veja Rio. Editora Abril. $1^{\circ}$ ago, 2007.

\footnotetext{
${ }^{7}$ Essa relação conflituosa foi percebida em outra pesquisa, realizada pela autora, sobre a Rua do Lavradio, localizada no bairro da Lapa, região central da cidade do Rio de Janeiro, em que antiquários e bares/restaurantes desenvolveram, nos últimos anos, uma relação de conflito de interesses, confronto e competição. No Rio de Janeiro, existem também outras ruas comerciais nas quais os conflitos se estabelecem entre os comerciantes com estabelecimentos legalizados e comerciantes ambulantes não legalizados, entre os comerciantes (legalizados ou não) e os moradores, mas este não é o caso da Rua Dias Ferreira.
} 
COSTA et al. Comportamento do consumidor: pesquisa etnográfica em shopping centers: Madureira Shopping Rio X São Conrado Fashion Mall. Cadernos Discentes Coppead. Rio de Janeiro, $\mathrm{n}^{\mathrm{o}}$ 1, p. 43-54, 2000.

CUNHA, N. \& MELLO, P. SAARA: reinventando etnicidades e ambiências urbanas num mercado popular carioca. 2010. Disponível em: http://lemetro5.blogspot.com/2005/ 08/saara-reinventando-etnicidades-e.html. Consult. 05 de fev de 2013.

DOUGLAS, M. \& ISHERWOOD, B. O mundo dos bens: para uma antropologia do consumo. Rio de Janeiro: Editora UFRJ. 2004

FRÚGOLI Jr, H. Os shoppings de São Paulo e a trama do urbano: um olhar antropológico. In:

PINTAUDI, Silvana M.; FRÚGOLI Jr., Heitor. (Org.). Shopping centers: espaço, cultura e modernidade nas cidades brasileiras. São Paulo: Ed. da Unesp, p. 75-92, 1992.

GEERTZ, C. The bazaar economy: information and search in peasant marketing. The American Economic Review, v. 68, n² 2, May, p. 28-32, 1976.

Suq: the bazaar economy in Sefrou. In: ROSEN, Lawrence et al. Meaning and order in contemporary Marocco: three essays in cultural analysis. Cambridge: Cambridge University Press, 1979

KERSHMAN, A. The London market guide. London: Metro Publications, 2008.

MARTINELLI, F. O original e o fake se encontram na esquina: uma etnografia do consumo nas ruas de Ipanema. In: XIV Congresso Brasileiro de Sociologia, Rio de Janeiro. Anais... Rio de Janeiro, 2009.

PEIRANO. M. Uma antropologia no plural. Brasília: UNB, 1991.

SAHLINS, M. Cultura e razão prática. Rio de Janeiro: Zahar, 1979.

SOARES, L. A. Entre a "casa" e a "rua": revisitando o espaço shopping center no Brasil. Cadernos Discentes Coppead. Rio de Janeiro, no 2, p. 80-92, 2000.

UDERHILL, P.. A magia dos shoppings. São Paulo: Campus, 2004 
Para citar essa obra:

CORRÊA, S. B. As ruas comerciais, o consumo e a vida social urbana: o universo dos ateliês da Rua Dias Ferreira In: RUA [online]. no. 21. Volume 1, p. 05 - 20 - ISSN 14132109. Junho/2015. Consultada no Portal Labeurb - Revista do Laboratório de Estudos Urbanos do Núcleo de Desenvolvimento da Criatividade.

http://www.labeurb.unicamp.br/rua/

Capa: Foto da autora. Visão geral da Rua Dias Ferreira.

Laboratório de Estudos Urbanos - LABEURB

Núcleo de Desenvolvimento da Criatividade - NUDECRI

Universidade Estadual de Campinas - UNICAMP

http://www.labeurb.unicamp.br/

Endereço:

LABEURB - LABORATÓRIO DE ESTUDOS URBANOS

UNICAMP/COCEN / NUDECRI

CAIXA POSTAL 6166

Campinas/SP - Brasil

CEP 13083-892

Fone/ Fax: (19) 3521-7900

Contato: http://www.labeurb.unicamp.br/contato 